\title{
Acute transverse myelitis after COVID-19 pneumonia
}

\author{
Maike Munz ${ }^{1}$ - Swen Wessendorf ${ }^{2} \cdot$ Georgios Koretsis $^{1} \cdot$ Friedemann Tewald $^{4} \cdot$ Reem Baegi $^{3} \cdot$ Stefan Krämer $^{3}$. \\ Michael Geissler ${ }^{2} \cdot$ Matthias Reinhard $^{1}$
}

Received: 28 April 2020 / Revised: 17 May 2020 / Accepted: 19 May 2020 / Published online: 26 May 2020

(c) Springer-Verlag GmbH Germany, part of Springer Nature 2020

\section{Background}

Neurological complications of SARS-CoV2 infection are increasingly recognized [1]. Recently, a SARS-CoV2 induced focal encephalitis was reported [2]. Here we describe a case of multifocal transverse myelitis following acute COVID-19 pneumonia.

\section{Case}

A 60-year-old patient was first admitted to our hospital with typical respiratory symptoms of COVID-19 infection without neurological symptoms. The polymerase chain reaction (PCR) test of the throat swab was positive for SARS-CoV2. A chest $\mathrm{X}$-ray showed mild bilateral ground-glass opacification. Laboratory findings revealed elevated C-reactive protein but normal white blood cell count. The patient's previous medical history was unremarkable other than hypertension (treated with ramipril and felodipine), mild fatty liver, and ureterolithiasis. Patients and family history revealed no signs of neurological disorders and he received no vaccination in the months before. He recovered rapidly

Maike Munz and Swen Weßendorf authors contributed equally.

Matthias Reinhard

m.reinhard@klinikum-esslingen.de

1 Department of Neurology and Clinical Neurophysiology, Medical Center Esslingen, Academic Teaching Hospital of the University of Tübingen, Hirschschlandstr. 97, 73730 Esslingen, Germany

2 Department of Gastroenterology and Oncology, Medical Center Esslingen, Academic Teaching Hospital of the University of Tübingen, Esslingen, Germany

3 Department of Radiology and Nuclear Medicine, Medical Center Esslingen, Academic Teaching Hospital of the University of Tübingen, Esslingen, Germany

4 Labor Prof. G. Enders MVZ, Stuttgart, Germany from COVID-19 pneumonia and was discharged home 5 days later without any symptoms.

Three days after discharge, he developed bladder dysfunction and progressive weakness of the lower limbs. He was unable to micturate or walk unaided. On re-admission two days later, clinical examination revealed hypesthesia below the Th9 level and a moderate spastic paraparesis. Babinski's sign was positive bilaterally. Cognition and cranial nerves were unaffected. General lab results were unremarkable including a nearly normalized c-reactive protein. A repeated throat swab showed a negative SARS-CoV2 PCR. Magnetic resonance imaging (MRI) of the spine revealed T2 signal hyperintensity of the thoracic spinal cord at Th9 level suggestive of acute transverse myelitis rather than multiple sclerosis [3] (Fig. 1a). Brain MRI showed no inflammatory changes. Cerebrospinal fluid (CSF) analysis was abnormal with lymphocytic pleocytosis $(16 / \mu \mathrm{l})$ and elevated protein level $(793 \mathrm{mg} / \mathrm{l})$. SARS-CoV2-PCR in the CSF and oligoclonal bands were negative. Further work-up was unremarkable including PCR for herpes simplex virus, varicella-zoster virus, antibodies against human herpesvirus 6, Epstein-Barr virus, and Hepatitis E, antineuronal antibody panel, Aquaporin-4, and myelin oligodendrocyte glycoprotein antibodies. Follow-up MRI on day 6 further showed a patchy hyperintensity of the thoracic myelon at Th9-10 and at Th3-5 level (Fig. 1d), suggestive of transverse myelitis. Repeated CSF analysis showed a slight increase in CSF lymphopleocytosis $(27 / \mu \mathrm{l})$ and protein levels $(1177 \mathrm{mg} / \mathrm{l})$. Repeated SARSCoV2-PCR in the CSF was negative. There was no specific intrathecal synthesis of Anti-SARS-CoV IgG.

Initial treatment with aciclovir and ceftriaxone intravenously was discontinued on day 8 after negative CSF results for respective infective agents. The patients' clinical status slightly improved 3 days after admission. Because of persisting symptoms and after negative workup for active infection, methylprednisolone was started on day 7 at a dose of $100 \mathrm{mg} / \mathrm{d}$. During the further course, the patient improved rapidly. Follow-up CSF on day 12 showed normalization of cell count $(3 / \mu \mathrm{l})$ and regressing protein levels $(734 \mathrm{mg} / \mathrm{l})$, no 


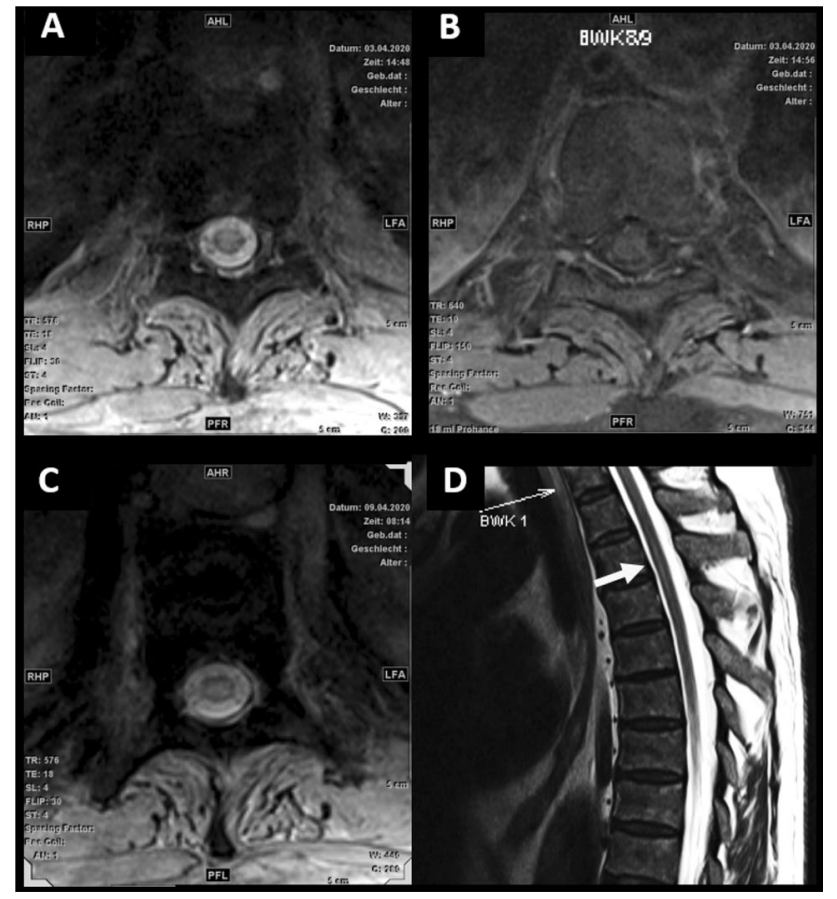

Fig. 1 MRI of the spine. a Day 1 (admission). T2 weighted axial imaging shows central hyperintensity on Th9 level. b Day 1: Axial T1 weighted image on the same level showed no enhancement after gadolinium. c Day 6: T2 axial slice on level Th9 with hyperintense edema. d Day 6: Longitudinal view of upper thoracic spine shows central hyperintensity on level Th3 (arrow)

oligoclonal bands. The patient was discharged home on day 13 with a slight spastic paraparesis and hypesthesia below Th9 level, but normal bladder function. He was able to walk independently. A steroid taper scheme was initiated.

\section{Discussion}

This case describes multifocal myelitis occurring shortly after COVID-19 infection. No other causes of myelitis could be identified after extensive workup. We assume a post-infectious etiology in terms of secondary immunogenic overreaction. Previously, others suggested a direct infection of the central nervous system by human coronaviruses like SARS or MERS [4]. The affection of the peripheral nervous system and muscles was described for SARS-CoV-1 [5]. Cases of Guillain-Barré Syndrome in association with severe COVID-19 infections were reported [6]. In a series of 58 severely affected COVID-19 patients, 67\% showed clinical corticospinal tract signs but received no spinal MRI [7]. Only one other case with suspected focal myelitis without imaging or serological confirmation is reported from Wuhan [8]. This patient improved with empiric multiple treatments including intravenous immunoglobulins, prednisolone, and antiviral agents. Our case shows that improvement might also occur with moderate steroid treatment, avoiding high doses because of uncertain effects on the immunogenic elimination of SARS-CoV2.

It remains unclear at present whether post-infectious myelitis after COVID-19 behaves differently from other virus infections. Increased awareness of spinal symptoms following COVID-19 is recommended.

\section{Compliance with ethical standards}

Conflicts of interest None.

Statement of ethics Written informed consent was obtained from the patient.

Disclosure statement The authors have no relevant financial or nonfinancial relationships to disclose.

\section{References}

1. Mao L, Jin H, Wang M, Hu Y, Chen S, He Q, Chang J, Hong C, Zhou Y, Wang D, Miao X, Li Y, Hu B (2020) Neurologic Manifestations of Hospitalized Patients With Coronavirus Disease 2019 in Wuhan China. JAMA Neurol. https://doi.org/10.1001/jamaneurol .2020 .1127

2. Moriguchi T, Harii N, Goto J, Harada D, Sugawara H, Takamino J, Ueno M, Sakata H, Kondo K, Myose N, Nakao A, Takeda M, Haro H, Inoue O, Suzuki-Inoue K, Kubokawa K, Ogihara S, Sasaki T, Kinouchi H, Kojin H, Ito M, Onishi H, Shimizu T, Sasaki Y, Enomoto N, Ishihara H, Furuya S, Yamamoto T, Shimada S (2020) pre-proof) A first Case of Meningitis/Encephalitis associated with SARS-Coronavirus-2. Int J Infect Dis PII S1201-9712(20):30195-30198

3. Bakshi R, Kinkel PR, Mechtler LL, Bates VE, Lindsay BD, Esposito SE, Kinkel WR (1998) Magnetic resonance imaging findings in 22 cases of myelitis: comparison between patients with and without multiple sclerosis. Eur J Neurol 5(1):35-48

4. Li Y, Bai W, Hashikawa Z (2020) The neuroinvasive potential of SARS-CoV2 may play a role in the respiratory failure of COVID19 patients. J Med Virol 2020:1-4

5. Tsai LK, Hsieh ST, Chao CC, Chen YC, Lin YH, Chang SC, Chang YC (2004) Neuromuscular disorders in severe acute respiratory syndrome. Arch Neurol 61(11):1669-1673

6. Toscano G, Palmerini F, Ravaglia S, Ruiz L, Invernizzi P, Cuzzoni G, Franciotta D, Baldanti F, Daturi R (2020) Guillain-Barré syndrome associated with SARS-CoV-2. N Engl J Med. https:// doi.org/10.1056/NEJMc2009191

7. Helms J, Kremer S, Merdji H, Clere-Jehl R, Schenck M, Kummerlen C, Collange O, Boulay C, Fafi-Kremer S, Ohana M, Anheim M, Meziani F (2020) Neurologic Features in Severe SARS-CoV-2 Infection. N Engl J Med. https://doi.org/10.1056/NEJMc2008597

8. Zhao K, Huang J, Dai D, Feng Y, Liu L, Nie S (2020 Preprint) Acute myelitis after SARS-CoV-2 infection: A case report https ://doi.org/10.1101/2020.03.16.20035105 